\title{
Dry or Steam Rolling of Soft Grains: Dairy and Beef Bioprocessing Perspectives
}

\section{Akbar Nikkhah*}

Chief Highly Distinguished Professor, Department of Animal Sciences, University of Zanjan, Iran

\begin{abstract}
This article yields pragmatic perspectives on dry-rolling vs. steam-rolling of barley and wheat grains for modern dairy and beef industries. Dry-rolling could suffice exposing soft cereal starch and protein to adequate (but not excess) ruminal microbial fermentation without compromising rumen health when dietary space for sufficient physically effective fibre is designed. In high-producing dairy and finishing beef diets, however, due to the highly concentrated cereal starch, steam-rolling could provide healthier rumen conditions over dry-rolling.
\end{abstract}

Keywords: Dry-rolling; Steam-rolling; Cereal grain; Dairy; Beef; Industry

\section{Introduction}

The objective of this article was to provide pragmatic perspectives on dry and steam-rolling of soft cereal grains for dairy and beef enterprises. Grains bioprocessing efficiency and economics have been controversial in modern global ruminant industries. Despite extensive research, many puzzling questions remain to be answered under practical scenarios [1-3]. A main question has been the comparative effectiveness of dryrolling vs. steam-rolling for dairy vs. beef ruminants.

Dry-rolled grains are produced via passing whole barley and wheat kernels through dry rollers aiming to break kernels into only few large particles or to yield rather thick and dense unbroken flakes. However, steam-rolling is conducted typically using corrugated rollers that bioprocess the already steamed barley or wheat kernels to produce rather thin and light flakes. As a result, dry-rolling demands lower costs than steam-rolling. In other words, steam-rolling would be justified economically only when the biological advantages of healthier rumen environment and increased productivity could overshadow the extra cost of equipment and labour [4-7].

Accordingly, when the goal is to just facilitate microbial attachment and gradual fermentation of starch and nitrogen compounds and not indeed to overdegrade grains rapidly, coarse dry-rolling would be an optimum bioprocessing choice. This is usually the case in mid and lowproducing dairy diets and starting and growing beef diets where rations contain lower and moderated grain levels.

However, when the aim is to rather moderate the fermentation rate to avoid rapid accumulation of organic acids and minimize occurrence of Subacute Rumen Acidosis (SARA) and inflammation, steam-rolling could prove superior over dry-rolling. This is because steam application may enhance inter-molecule bonds and reduce risks of overfermentation and SARA while improving microbial mass production. This is the scenario that may be particularly encountered in high-producing high-consuming dairy cows and finishing beef cattle where diets contain considerably high portions of barley and wheat starch that must be controlled in degradation extent and rate [8].

\section{Implications}

Whether or when to dry-roll or steam-roll soft grains has been a question in modern ruminant farms. Dry-rolling is less expensive than steam-rolling and is thus justified taking advantage of when rations contain lower and moderated levels of barley and wheat grains, such as growing beef and lower-producing and dry-cow dairy diets. Steamrolling, despite the equipment and cost, could prove economical when rations have higher and challenging rates of grains. Thus, steam-rolling would be an optimum choice of bioprocessing in large ruminant enterprises where dry-rolling may not suffice managing rumen conditions for different groups of animals.

\section{Acknowledgments}

The Iran's Ministry of Science Research and Technology, National Elite Foundation, and University of Zanjan are gratefully acknowledged for supporting the author's global programs of optimizing science edification in the new millennium.

\section{References}

1. Nikkhah A (2012) Barley grain for ruminants: A global treasure or tragedy. $J$ Anim Sci Biotechnol 3: 22.

2. Nikkhah A (2014) Bioprocessing of soft cereals for postmodern ruminants: Ascertaining decades of uncertainty. J Bioprocess Biotech 4: e116.

3. NRC (2001) National Research Council. Nutrient Requirements of Dairy Cattle 7th revised edition. National Academic Press, Washington, DC, USA.

4. Nikkhah A (2014) Bioprocessing of barley for food-producing ruminants: A workable dilemma. J Bioprocess Biotech 4: e113.

5. Nikkhah A (2014) Steam bioprocessing philosophy of cereals for ruminants: time for a new history. J. Bioprocess Biotech 4: e114.

6. Nikkhah A (2014) Grinding as a most economical healthy bioprocessing biotechnique of cereals for postmodern ruminants. J Bioprocess Biotech 5 e119.

7. Nikkhah A (2015) Production curve management of starch nutrition in ruminants: A global biotechnique. J Bioprocess Biotech.

8. Nikkhah A (2015) Cereals bond trounces subacute rumen acidosis. Int J Vet Health Sci Res 3: 1-2.

*Corresponding author: Akbar Nikkhah, Chief Highly Distinguished Professor, Department of Animal Sciences, Faculty of Agricultural Sciences, University of Zanjan, Zanjan, Iran, National Elite Foundation, Tehran, Iran, Tel: +98-24-350328-01; Fax: +98-24-350-332-02; E-mail: nikkhah@znu.ac.ir

Received February 09, 2015; Accepted February 10, 2015; Published February 13, 2015

Citation: Nikkhah A (2015) Dry or Steam Rolling of Soft Grains: Dairy and Beef Bioprocessing Perspectives. J Bioprocess Biotech 5: e124 doi:10.4172/21559821.1000e124

Copyright: (c) 2015 Nikkhah A. This is an open-access article distributed unde the terms of the Creative Commons Attribution License, which permits unrestricted use, distribution, and reproduction in any medium, provided the original author and source are credited. 